\title{
Variant morphology in upper urinary tract urothelial carcinoma: a fourteen-year case series of biopsy and resection specimens
}

Hiroyuki Hayashi, MD ${ }^{\mathrm{a}}$, Steven Mann, MD ${ }^{\mathrm{a}}$, Chia-sui Kao, $\mathrm{MD}^{2}$, David Grignon, MD, $\operatorname{FRCP}(C)^{\mathrm{a}}$, Muhammad T. Idrees, $\mathrm{MD}^{\mathrm{a}}$

${ }^{a}$ Department of Pathology and Laboratory Medicine, Indiana University School of Medicine, Indianapolis, IN 46202.

Present addresses:

${ }^{1}$ Department of Pathology, Fukuoka University Hospital, Fukuoka, Japan.

${ }^{2}$ Department of Pathology, Stanford University Medical Center, Stanford, CA 94305.

Corresponding author: Muhammad T. Idrees, MBBS, MD, Department of Pathology, Indiana University School of Medicine, 350 West 11th Street, Indianapolis, IN 46020. Phone: $317-$ 491-6000; fax: 317-491-6419; e-mail: midrees@iupui.edu

Keywords: Upper urinary tract, urothelial carcinoma; variant morphology

Running head: Variant upper urinary tract urothelial carcinoma

The authors declare that they have no significant conflicts of interest pertaining to this study.

This research did not receive any specific grant from funding agencies in the public, commercial, or not-for-profit sectors.

This is the author's manuscript of the article published in final edited form as: Hayashi, H., Mann, S., Kao, C., Grignon, D., \& Idrees, M. T. (2017). Variant morphology in upper urinary tract urothelial carcinoma: a fourteen-year case series of biopsy and resection specimens. Human Pathology. https://doi.org/10.1016/j.humpath.2017.05.001 


\section{Abstract}

Upper urinary tract urothelial carcinoma exhibiting variant morphology, especially in highergrade tumors, is a recognized phenomenon but has not been comparatively studied in biopsy versus resection material. We studied the morphologic patterns and clinicopathological features, and provide a comparison between biopsy and resection specimens. Consultation cases were evaluated separately to investigate for possible consultation bias. A total of 383 inhouse cases from 352 patients including 314 resection specimens and 69 biopsies from 2001 2014 were reviewed from a single institution. Histologic type, tumor grade, invasion, pathologic stage, nodal status, metastasis, and the presence and type of variant morphology for each case were evaluated. Variant morphology was identified in 5 biopsy specimens $(7.2 \%)$ and 42 resection specimens $(13.4 \%)$. The most common variant morphologic pattern was squamous differentiation (16 cases, $4.5 \%)$ followed by an inverted growth pattern ( 8 cases, $2.2 \%$ ). The presence of variant morphology in resection specimens had a significant association with higher tumor grade, higher $\mathrm{pT}$ stage, and non-papillary configuration. Out of 69 patients with biopsies, 31 had a subsequent resection. In comparison, 181 consultation cases from 168 patients showed variant morphology in six biopsies (7.1\%) and twenty-seven resections $(28.1 \%)$. In conclusion, the frequency of recognizing variant morphology in biopsies is about one-half of that in resections. The inclusion of consultation cases can inflate the incidence of variant morphology. As a result, the frequency of variant morphology in our in-house cases is lower than the percentage reported in the literature, most likely secondary to a consultation bias.

Keywords: Upper urinary tract, urothelial carcinoma; variant 


\section{1}

\section{Introduction}

Urothelial neoplasms of upper urinary tract are uncommon, accounting for approximately $5 \%$ of all epithelial tumors of the urinary tract [1]. Eighty percent of those are malignant, with urothelial carcinoma (UC) accounting for 90\%. From 2004-2010, the percentage of in situ cases increased while stage IV cases have decreased [2]. Upper urinary tract urothelial carcinoma (UTUC) exhibiting variant morphology is a well-recognized phenomenon, and has been reported to be associated with a higher grade, higher stage, higher frequency of lymphovascular invasion, and increased recurrence [3-7].

Recognition of variant morphology is not only essential for management decisions but also necessary to rule out metastasis or secondary involvement from adjacent malignancies [8]. The reported frequency of UTUC variant morphology in surgical resections; i.e., nephroureterectomy or ureterectomy, has ranged from $12-40 \%$ in the larger published series [4-7]. However, the frequency of variant morphology in biopsies and their subsequent resection specimens has not been previously reported. We analyzed a large volume of cases from a single institution, comparing findings from both in-house and consultation cases, in order to investigate the true incidence of variant morphology in UTUC and determine the presence and significance of the consultation bias.

\section{2}

\section{Materials and Methods}

An electronic data search was performed from our institutional files from January 2001 through December 2014 to include all biopsies and surgical resections with a final 
diagnosis of UTUC. Included cases of UTUC were from nephrectomies, nephroureterectomies, and ureterectomies, as well as all biopsies from the portion of the urinary tract above the urinary bladder (renal pelvis and ureter). The cases were separated based on service type: in-house or consultation. In-house cases included all biopsy and resection procedures performed at the hospital sites within our institution and directly served by our department. Consultation cases were cases sent to our department from other institutions for expert interpretation.

All case documentation was analyzed and the diagnoses were confirmed by reviewing the corresponding hematoxylin and eosin-stained sections. The clinical information of each patient was reviewed from all available electronic medical records, and the following data points were recorded: (1) age at time of diagnosis, (2) gender, (3) stage, (4) development of recurrence and/or metastasis, and (5) status of disease at last follow-up.

These UTUC cases were reviewed for various histologic features, including configuration, grade of tumor, pathologic stage, vascular invasion, and the presence and type of variant morphology. The configuration was classified as papillary or non-papillary based on the architecture. Tumors were classified as low grade or high grade according to criteria set by the World Health Organization (WHO)/International Society of Urological Pathology (ISUP) grading system [9]. Tumor staging was performed according to the 2010 American Joint Committee on Cancer TNM staging system [10]. We defined low pT to be pTa, pTis, and pT1. Cases with a pT of pT2 or higher were designated as high pT for our analysis. Variant morphology was classified using the WHO 2016 classification and additional recently reported patterns in literature $[8,9,11-13]$. 
Statistical analysis between cases with and without variant morphology and for clinicopathologic factors was performed using the chi-square test or the Fisher exact test. For all data reported, results with a $p$ value $<0.05$ were considered statistically significant. All data was analyzed using EZR (Saitama Medical Center, Jichi Medical University), which is a graphical user interface for R (The R Foundation for Statistical Computing, version 3.1.2) [14].

In concordance with our institutional policy, all patients seen within our hospital system have given consent for materials to be used for research purposes in an anonymous fashion. Furthermore, this study is granted exemption status by our Institutional Review Board.

\section{3}

\section{Results}

Over the fourteen-year study period, a total of 383 in-house cases from 352 patients were identified. These included 69 biopsies and 314 resections (202 nephroureterectomies, 112 ureterectomies). The clinicopathological characteristics associated with variant morphology in biopsies and resections from in-house cases are provided in Table 1. The patients ranged in age from 37-95 years (mean 70.6 years); the male to female ratio was 1.6:1. The follow-up time ranged from 1-139 months (median, 8 months). The most common architecture was papillary, followed by infiltrative/nodular (Figure 1A, B). Overall, 46 cases $(13 \%)$ showed the presence of variant morphology, of which 44 cases $(95.6 \%)$ were highgrade, and 39 cases $(84.7 \%)$ were invasive. The presence of variant morphology had a significant correlation with non-papillary configuration $(P=0.013)$, high grade $(P=0.0127)$, 
and high pT stage $(P=0.0002)$ (Table 2$)$.

During the same time period, a total of 181 consultation cases from 168 patients were identified. These included 85 biopsies and 96 resections (77 nephroureterectomies, 19 ureterectomies). Clinical information provided with consultation cases was often limited to age, sex, and operative procedure. The patients ranged in age from 14-87 years (mean 64.2 years); the male to female ratio was 1.1:1. The follow-up time was not available. The most common architecture was papillary. Overall, 33 cases $(18 \%)$ showed the presence of variant morphology, of which 44 cases $(87.9 \%)$ were of high-grade morphology.

\subsection{1}

\section{Biopsies:}

A total of 69 in-house biopsies from the upper urinary tract with a diagnosis of urothelial carcinoma were identified. Of these, 31 cases had subsequent resections. Patient age ranged from 52-80 years (mean 69.9 years), and the male to female ratio was 3:2. Five cases $(7.3 \%)$ showed the presence of variant morphology and four of these cases $(80.0 \%)$ were high-grade tumors. Three of these 5 cases $(60.0 \%)$ showed invasion. Variant morphology in biopsy specimens showed no significant correlation with configuration ( $P=0.241)$, grade $(P=0.643)$, or higher $\mathrm{pT}$ stage $(P=0.211)$ (Tables 2 and 3$)$.

A total of 85 consultation biopsies diagnosed as UTUC were identified. Of these, 13 cases included subsequent resections. Patient age ranged from 14-87 years (mean 68.4 years), and the male to female ratio was $1.5: 1$. Six cases $(7.1 \%)$ showed the presence of variant morphology and five of these cases $(83.3 \%)$ were high-grade tumors.

\subsection{2}




\section{Resections:}

For the 314 in-house resection cases, the patient age ranged from 37-95 years (mean70.6 years), and the male to female ratio was $2: 1$. Forty-two cases $(13.4 \%)$ displayed variant morphology, 40 (95.2\%) of which occurred in high-grade tumors, and $36(85.7 \%)$ in invasive carcinomas. Unlike in the biopsy group, the presence of variant morphology had a significant correlation with non-papillary configuration $(P=0.013)$, high grade $(P=0.0127)$, and high $\mathrm{pT}$ stage $(P=0.0002)$ (Tables 2 and 4$)$.

For the 96 consultation resection cases, the patient age ranged from 21-87 years (mean 66.0 years), and the male to female ratio was $0.96: 1$. Twenty-seven cases $(28.1 \%)$ displayed variant morphology, 24 (88.9\%) of which occurred in high-grade tumors.

\subsection{3}

\section{Variant morphologic patterns:}

Of 352 in-house patients, 306 were cases of usual urothelial carcinoma and the remaining 46 patients displayed variant morphology. Squamous differentiation (16 cases, 4.1\%) was the most common, followed by inverted growth pattern ( 8 cases, $2.5 \%$ ), sarcomatoid ( 7 cases, 1.8\%), glandular differentiation (6 cases, 1.6\%), and micropapillary (4 cases, 0.9\%) (Table 5; Figure 1). Other less common patterns included plasmacytoid (2 cases, $0.6 \%$ ), giant cell ( 1 case, $0.3 \%$ ), and lymphoepithelioma-like ( 1 case, $0.3 \%$ ) (Figure 2 ). Two cases with squamous differentiation also had sarcomatoid and glandular differentiation respectively. Only two of 31 cases that included both a biopsy and subsequent resection showed inverted growth pattern in both (Figure 1D). A summary of the types of divergent morphology over different grades and stages in biopsies and resections is provided in Table 6 . 
Among the 181 consultation UTUC cases reviewed, 33 cases displayed variant morphology. The most common variant types of these were squamous differentiation and sarcomatoid ( 9 cases, $4.8 \%$, each), followed by inverted growth pattern ( 7 cases, $3.7 \%$ ) and glandular differentiation (6 cases, 3.2\%). Less common patterns were plasmacytoid (3 cases, $1.6 \%$ ), small cell ( 2 cases, $1.1 \%$ ), and trophoblastic ( 1 case, $0.5 \%$ ). A mixture of variant patterns was seen in four cases. Each contained squamous differentiation and another component: sarcomatoid, glandular differentiation, or the combination of glandular differentiation and sarcomatoid (chondroid heterologous component). Of the sarcomatoid type cases, one contained osteoclast-like giant cells and another was composed of almost entirely rhabdoid cells. One case with squamous differentiation also contained abundant myxoid stroma. None of the consultation cases displaying variant morphology included both a biopsy and subsequent resection for comparison. A comparison of variant patterns from inhouse and consultation cases is provided in Table 5.

\section{4}

\section{Discussion}

The frequency of variant morphology in UTUC has previously been reported as being between $12.0 \%$ and $24.2 \%$ in a limited number of large resection series $[6,7,15]$. The incidence in the renal pelvis has been reported to be as high as $40 \%$ in the literature $[4,5]$. However, our findings are that the frequency of variant morphology is nearer to the low end of the percentage range reported. It is possible that the reporting studies represent cohorts of patients not just from hospital and community practices, but also including unique consultations, thus leading to a higher percentage of variant morphology. It is also likely that 
cases sent by general pathologists for expert consultation have a greater incidence of morphological variants because of their diagnostically challenging nature.

To investigate this source of bias we excluded all the consultation cases from statistical analyses and report consultation data separately from our in-house patients. To our knowledge, this study is one of the largest series examining variant UTUC patterns. In our opinion, the results of our in-house group provide an accurate incidence of this entity in general practice.

The spectrum of variant morphologies of UTUC is similar to that from the urinary bladder [1]. Previous reports from resection specimens have included examples of UC with squamous differentiation, UC with glandular differentiation, microcystic UC, micropapillary UC, UC with inverted growth pattern, UC with choriocarcinoma or syncytiotrophoblastic giant cells (now termed UC with trophoblastic differentiation [9]), sarcomatoid UC (including cases with heterologous components present such as rhabdoid cells or chondrosarcoma [9]), lymphoepithelioma-like UC, nested UC, plasmacytoid UC, signet ring cell (now included in plasmacytoid UC if no extracellular mucin component is present [9]), small cell carcinoma, clear cell UC, and lipid-rich UC, osteoclast-rich poorly undifferentiated carcinoma, and UC with pseudosarcomatous stromal changes [4-6, 16-35]. In our study, the most frequent type from in-house resections was squamous differentiation, as in a previously reported series [6]. The frequency of squamous differentiation has been reported to range from $9.9 \%-18 \%$, but our study showed a lower frequency of squamous differentiation (4.5\%), squamous differentiation combined with sarcomatoid (0.3\%), and squamous differentiation combined with glandular differentiation $(0.3 \%)$ patterns $[3,4,6]$. One possible explanation 
for this variation in squamous differentiation recognition could be the use of varying criteria by different pathologists.

The presence of variant morphology in resection specimens (in-house cases) showed a significant correlation with high grade and high pT stage. In the urinary tract, variant differentiation frequently corresponds with higher grade and stage of urothelial cancer [9]. Sakano et al. reported that UTUC with variant histology was significantly associated with advanced pathological $\mathrm{T}$ stage ( $\mathrm{pT} \geq 3$ ), higher tumor grade (G3), and more frequent lymphovascular invasion [7]. On univariable analysis, variant histology was associated with disease recurrence and cancer specific mortality; however, multivariate analysis did not show an association with cancer specific mortality $[6,7]$. In our study, it is not possible to determine an association between prognosis and variant morphology because the follow-up time (mean 8 months) was too short for practical analysis. Variant morphology in resections also showed a significant correlation with the non-papillary configuration. Rink et al. also reported a similar correlation. Remzi et al. reported that pT2 and higher stage tumors tend to have the non-papillary pattern [30]. Tumor architecture has also been reported as an independent predictor of cancer recurrence and cancer-specific mortality [24, 30]. Therefore, it is important to pay attention to the configuration of UTUC cases to detect variant morphology and for accurate prognostication.

We assessed the frequency of variant morphologies of UTUC in biopsies and compared it to resections. The frequency in in-house biopsies was $7.2 \%$, about a one-half of that found in in-house resections. Moreover, unlike in resections, variant morphology in a biopsy had no association with configuration, grade, or pT stage. The most likely explanation 
is the smaller sample size and superficial nature of these specimens precluded thorough assessment. This is supported by our observations that grade and morphologic patterns are more accurately assessed in resection specimens as compared to biopsy material. In a larger study, it was documented that in the urinary bladder, out of 589 transurethral biopsies of UC, 115 cases $(19.5 \%)$ demonstrated variant histologic differentiation [31]. Unlike these urinary bladder biopsies, upper urinary tract biopsies seem to have a lower detection rate of variant morphology and it is important to consider this when making management decisions. The fact that upper urinary tract biopsies are typically much smaller than bladder biopsies most likely contributes to this. Additionally, it might be difficult to distinguish cases of primary UC from metastasis, or direct invasion from another malignancy, on the basis of biopsy alone when findings demonstrate a variant morphology.

In this study, 31 patients had a biopsy followed by surgical resection (in-house). Two patients $(6.5 \%)$ displayed variant morphology on the preoperative biopsy. One showed lowgrade papillary UC with inverted growth pattern on biopsy. The final postoperative diagnosis was high-grade papillary UC with inverted growth pattern, and the stage was pT2pN2. The other showed high-grade papillary UC with inverted growth pattern both on biopsy and resection. This emphasizes that biopsy may provide limited information regarding grade and the extent of tumor.

In summary, our study shows that variant morphology is found in $12.6 \%$ of UTUC. This was more often recognized in the resections (13.2\%) than in biopsies (7.2\%). The presence of variant morphology in resections had a significant association with non-papillary configuration, higher grade, and high pT stage. We conclude that the incidence of variant 
morphology is lower in the general population than previously reported, most likely due to a consultation bias. Lastly, biopsy specimens may provide low sensitivity information regarding the presence of variant morphology. 


\section{References}

1. Genega EM, Porter CR. Urothelial neoplasms of the kidney and ureter. An epidemiologic, pathologic, and clinical review. Am J Clin Pathol 2002;117 Suppl;S36-48.

2. Altekruse SF, Dickie L, Wu XC, Hsieh MC, Wu M, Lee R, Delacroix S, Jr. Clinical and prognostic factors for renal parenchymal, pelvis, and ureter cancers in SEER registries: collaborative stage data collection system, version 2. Cancer 2014;120 Suppl 23;3826-3835. 3. Langner C, Hutterer G, Chromecki T, Rehak P, Zigeuner R. Patterns of invasion and histological growth as prognostic indicators in urothelial carcinoma of the upper urinary tract. Virchows Arch 2006;448;604-611.

4. Perez-Montiel D, Wakely PE, Hes O, Michal M, Suster S. High-grade urothelial carcinoma of the renal pelvis: clinicopathologic study of 108 cases with emphasis on unusual morphologic variants. Mod Pathol 2006;19;494-503.

5. Xiao GQ, Unger PD. Renal pelvic urothelial carcinoma with divergent morphology. Ann Diagn Pathol 2010;14;74-80.

6. Rink M, Robinson BD, Green DA, Cha EK, Hansen J, Comploj E, Margulis V, Raman JD, Ng CK, Remzi M, Bensalah K, Kabbani W, Haitel A, Rioux-Leclercq N, Guo CC, Chun FK, Kikuchi E, Kassouf W, Sircar K, Sun M, Sonpavde G, Lotan Y, Pycha A, Karakiewicz PI, Scherr DS, Shariat SF. Impact of histological variants on clinical outcomes of patients with upper urinary tract urothelial carcinoma. J Urol 2012;188;398-404.

7. Sakano S, Matsuyama H, Kamiryo Y, Hayashida S, Yamamoto N, Kaneda Y, Nasu T, Baba Y, Shimabukuro T, Suga A, Yamamoto M, Aoki A, Takai K, Yoshihiro S, Oba K, Yamaguchi Uro-Oncology Group. Impact of variant histology on disease aggressiveness and 
outcome after nephroureterectomy in Japanese patients with upper tract urothelial carcinoma. Int J Clin Oncol 2015;20;362-368.

8. Amin MB. Histological variants of urothelial carcinoma: diagnostic, therapeutic and prognostic implications. Mod Pathol 2009;22 Suppl 2;S96-S118.

9. Moch H, Humphrey PA, Ulbright TM, et al. WHO classification of tumours of tumours of the urinary system and male genital organs. 4th ed ed:IARC Press, 2016.

10. Edge SB, Byrd DR, Compton CC. AJCC cancer staging manual. 7th ed ed: Springer, 2010.

11. Amin MB, Srigley JR, Grignon DJ, Reuter VE, Humphrey PA, Cohen MB, Hammond ME, Cancer Committee CoAP. Updated protocol for the examination of specimens from patients with carcinoma of the urinary bladder, ureter, and renal pelvis. Arch Pathol Lab Med $2003 ; 127 ; 1263-1279$.

12. Nigwekar P, Amin MB. The many faces of urothelial carcinoma: an update with an emphasis on recently described variants. Adv Anat Pathol 2008;15;218-233.

13. Amin MB, Smith SC, Reuter VE, Epstein JI, Grignon DJ, Hansel DE, Lin O, McKenney JK, Montironi R, Paner GP, Al-Ahmadie HA, Algaba F, Ali S, Alvarado-Cabrero I, Bubendorf L, Cheng L, Cheville JC, Kristiansen G, Cote RJ, Delahunt B, Eble JN, Genega EM, Gulmann C, Hartmann A, Langner C, Lopez-Beltran A, Magi-Galluzzi C, Merce J, Netto GJ, Oliva E, Rao P, Ro JY, Srigley JR, Tickoo SK, Tsuzuki T, Umar SA, Van der Kwast T, Young RH, Soloway MS. Update for the practicing pathologist: The International Consultation On Urologic Disease-European association of urology consultation on bladder cancer. Mod Pathol 2015;28;612-630. 
14. Kanda Y. Investigation of the freely available easy-to-use software 'EZR' for medical statistics. Bone Marrow Transplant 2013;48;452-458.

15. Shibing Y, Turun S, Qiang W, Junhao L, Haichao Y, Shengqiang Q, Ping H, Dehong C. Effect of concomitant variant histology on the prognosis of patients with upper urinary tract urothelial carcinoma after radical nephroureterectomy. Urol Oncol 2015;33;204 e209216.

16. Baydar D, Amin MB, Epstein JI. Osteoclast-rich undifferentiated carcinomas of the urinary tract. Mod Pathol 2006;19;161-171.

17. Darko A, Das K, Bhalla RS, Heller D. Carcinosarcoma of the ureter: report of a case with unusual histology and review of the literature. Int J Urol 2006;13;1528-1531.

18. Guo CC, Tamboli P, Czerniak B. Micropapillary variant of urothelial carcinoma in the upper urinary tract: a clinicopathologic study of 11 cases. Arch Pathol Lab Med 2009;133;6266.

19. Gupta R, Paner GP, Amin MB. Neoplasms of the upper urinary tract: a review with focus on urothelial carcinoma of the pelvicalyceal system and aspects related to its diagnosis and reporting. Adv Anat Pathol 2008;15;127-139.

20. Keck B, Giedl J, Kunath F, Goebell PJ, Engehausen DG, Hartmann A, Wullich B. Clinical course of plasmacytoid urothelial carcinoma of the upper urinary tract: a case report. Urol Int 2012;89;120-122.

21. Kuroda N, Naroda T, Tamura M, Perez-Montiel D, Michal M, Hes O. High-grade urothelial carcinoma, plasmacytoid variant, of the renal pelvis with osteoclast-like giant cells and focal rhabdoid features. Pol J Pathol 2014;65;237-240. 
22. Lau SK. Nested variant of urothelial carcinoma of the renal pelvis. Pathol Res Pract $2009 ; 205 ; 508-512$.

23. Leroy X, Gonzalez S, Zini L, Aubert S. Lipoid-cell variant of urothelial carcinoma: a clinicopathologic and immunohistochemical study of five cases. Am J Surg Pathol $2007 ; 31 ; 770-773$.

24. Margulis V, Shariat SF, Matin SF, Kamat AM, Zigeuner R, Kikuchi E, Lotan Y, Weizer A, Raman JD, Wood CG, Upper Tract Urothelial Carcinoma CollaborationThe Upper Tract Urothelial Carcinoma C. Outcomes of radical nephroureterectomy: a series from the Upper Tract Urothelial Carcinoma Collaboration. Cancer 2009;115;1224-1233.

25. Masson-Lecomte A, Colin P, Bozzini G, Nison L, de La Taille A, Comperat E, Zerbib M, Rozet F, Cathelineau X, Valeri A, Ruffion A, Guy L, Droupy S, Cussenot O, Roupret M. Impact of micropapillary histological variant on survival after radical nephroureterectomy for upper tract urothelial carcinoma. World J Urol 2014;32;531-537.

26. McCash SI, Unger P, Dillon R, Xiao GQ. Undifferentiated carcinoma of the renal pelvis with osteoclast-like giant cells: a report of two cases. APMIS 2010;118;407-412.

27. Ng KF, Chen TC, Chang PL. Lymphoepithelioma-like carcinoma of the ureter. J Urol $1999 ; 161 ; 1277-1278$.

28. Pacchioni D, Bosco M, Allia E, Mussa B, Mikuz G, Bussolati G. Microcystic urothelial cell carcinoma with neuroendocrine differentiation arising in renal pelvis. Report of a case. Virchows Arch 2009;454;223-227.

29. Parwani AV, Herawi M, Volmar K, Tsay SH, Epstein JI. Urothelial carcinoma with rhabdoid features: report of 6 cases. Hum Pathol 2006;37;168-172. 
30. Remzi M, Haitel A, Margulis V, Karakiewicz P, Montorsi F, Kikuchi E, Zigeuner R, Weizer A, Bolenz C, Bensalah K, Suardi N, Raman JD, Lotan Y, Waldert M, Ng CK, Fernandez M, Koppie TM, Strobel P, Kabbani W, Murai M, Langner C, Roscigno M, Wheat J, Guo CC, Wood CG, Shariat SF. Tumour architecture is an independent predictor of outcomes after nephroureterectomy: a multi-institutional analysis of 1363 patients. BJU Int 2009; 103;307-311.

31. Shah RB, Montgomery JS, Montie JE, Kunju LP. Variant (divergent) histologic differentiation in urothelial carcinoma is under-recognized in community practice: impact of mandatory central pathology review at a large referral hospital. Urol Oncol 2013;31;16501655.

32. Terai A, Terada N, Ichioka K, Matsui Y, Yoshimura K, Wani Y. Lymphoepitheliomalike carcinoma of the ureter. Urology 2005;66;1109.

33. Vermeulen P, Hoekx L, Colpaert C, Wyndaele JJ, Van Marck E. Biphasic sarcomatoid carcinoma (carcinosarcoma) of the renal pelvis with heterologous chondrogenic differentiation. Virchows Arch 2000;437;194-197.

34. Wang X, MacLennan GT, Zhang S, Montironi R, Lopez-Beltran A, Tan PH, Foster S, Baldridge LA, Cheng L. Sarcomatoid carcinoma of the upper urinary tract: clinical outcome and molecular characterization. Hum Pathol 2009;40;211-217.

35. Zettl A, Konrad MA, Polzin S, Ehsan A, Riedmiller H, Muller-Hermelink HK, Ott G. Urothelial carcinoma of the renal pelvis with choriocarcinomatous features: genetic evidence of clonal evolution. Hum Pathol 2002;33;1234-1237. 


\section{Figure legends}

Figure 1. A, Papillary high grade urothelial carcinoma (right) adjacent to kidney parenchyma (left) (H\&E 40X). B, High grade urothelial carcinoma with an infiltrative pattern (upper right) and nodular pattern (lower left) (H\&E 100X). C, Urothelial carcinoma with keratinizing squamous differentiation (H\&E 100X). D, Urothelial carcinoma showing predominant inverted growth pattern (H\&E 200X). E, Urothelial carcinoma with a sarcomatoid component (H\&E 40X). F, Urothelial carcinoma with glandular differentiation (H\&E 200X).

Figure 2. Less commonly observed variant morphologies in upper urinary tract urothelial carcinoma. A, Plasmacytoid urothelial carcinoma, tumor cells with characteristic plasmacytoid morphology forming discohesive sheets infiltrating a fibrous stroma (H\&E 200X). B, Lymphoepithelioma-like differentiation, an abundant lymphoid infiltrate surrounding and obscuring urothelial tumor cells (H\&E 200X). C, Urothelial carcinoma with abundant myxoid stroma, single and groups of cells floating in mucin (H\&E 100X). D, Giant cell urothelial carcinoma, large pleomorphic cells with prominent giant cell morphology (H\&E 200X). 


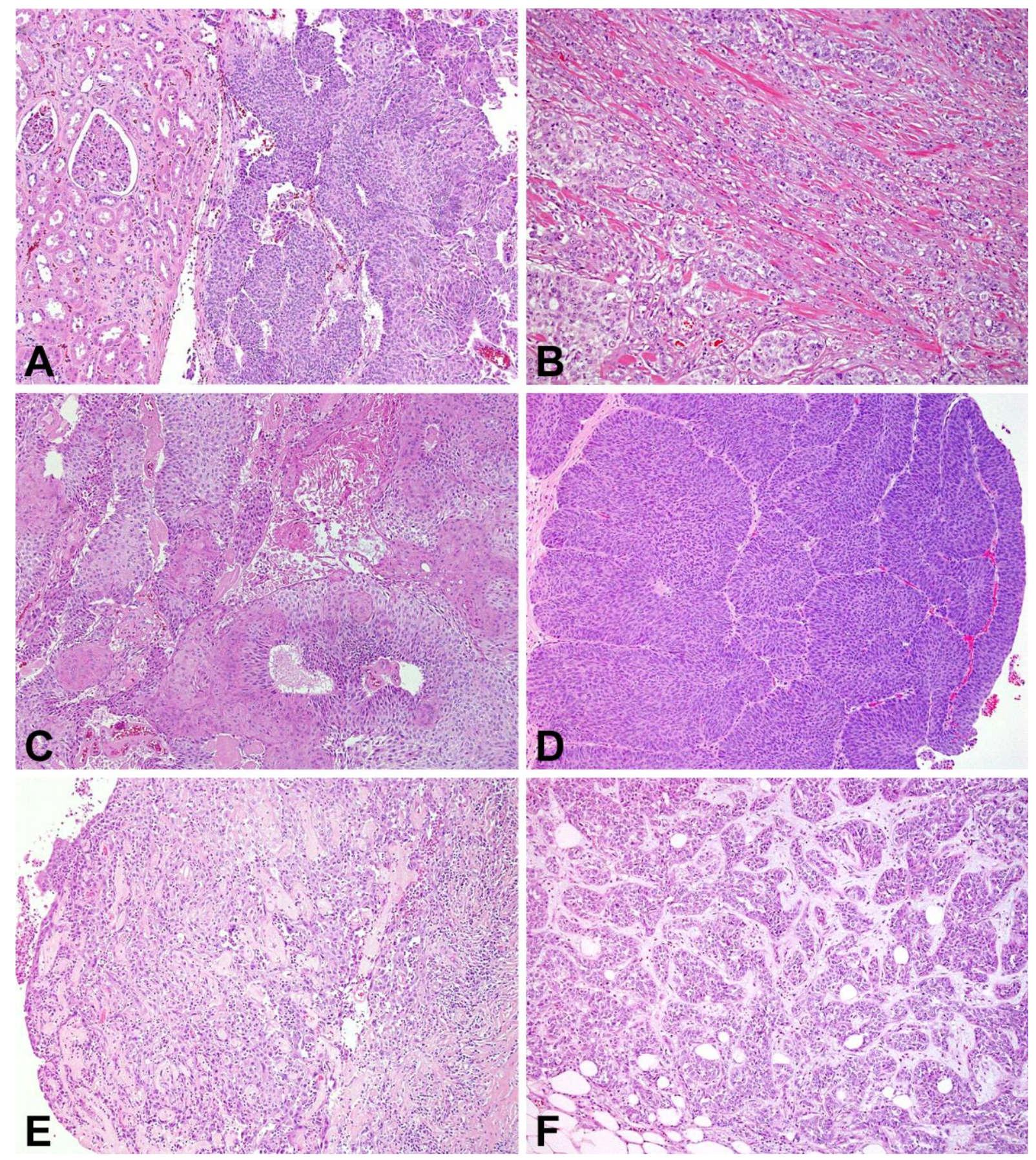

Figure 1 

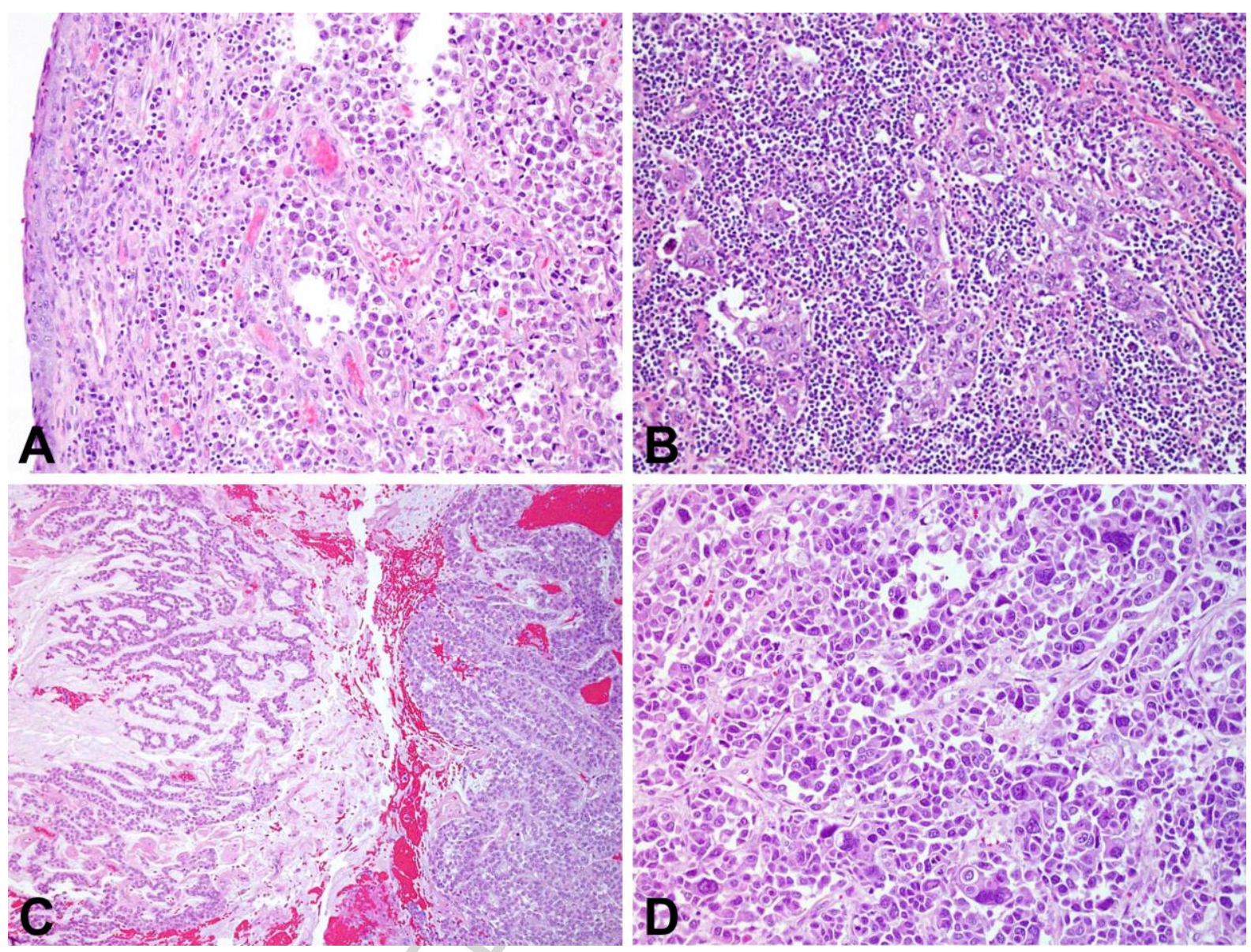

Figure 2 
Table 1. Variant morphology and clinical characteristics of in-house cases of upper urinary tract urothelial carcinoma

\begin{tabular}{|c|c|c|c|c|}
\hline & \multicolumn{2}{|c|}{$\begin{array}{c}\text { Variant morphology } \\
\text { in biopsies } \\
n=69(100 \%)\end{array}$} & \multicolumn{2}{|c|}{$\begin{array}{c}\text { Variant morphology } \\
\text { in resections } \\
\mathrm{n}=314(100 \%)\end{array}$} \\
\hline & $\begin{array}{c}\text { Present (\%) } \\
5^{*}(7.3)\end{array}$ & $\begin{array}{l}\text { Absent (\%) } \\
64(92.7)\end{array}$ & $\begin{array}{l}\text { Present (\%) } \\
42 *(13.4)\end{array}$ & $\begin{array}{l}\text { Absent (\%) } \\
272(86.6)\end{array}$ \\
\hline \multicolumn{5}{|l|}{ Age } \\
\hline$\leq 70$ & $4(80)$ & $30(46.9)$ & $16(38.1)$ & $126(46.2)$ \\
\hline$>70$ & $1(20)$ & $34(53.1)$ & $26(61.9)$ & $146(53.8)$ \\
\hline \multicolumn{5}{|l|}{ Sex } \\
\hline M & $3(60)$ & $38(59.4)$ & $27(64.3)$ & $171(62.9)$ \\
\hline $\mathrm{F}$ & $2(40)$ & $26(40.6)$ & $15(35.7)$ & $101(37.1)$ \\
\hline \multicolumn{5}{|l|}{ Surgery } \\
\hline Nephroureterectomy & & & $30(71.4)$ & $172(63.3)$ \\
\hline Ureterectomy & & & $12(28.6)$ & $100(36.7)$ \\
\hline \multicolumn{5}{|l|}{ Chemotherapy } \\
\hline None & & & $30(71.4)$ & $221(81.5)$ \\
\hline Neoadjuvant & & & $11(26.2)$ & $40(14.5)$ \\
\hline Unknown & & & $1(2.4)$ & $11(4.0)$ \\
\hline Follow-up (month) & & & $<1-139$ & $<1-89$ \\
\hline Died from UTUC & & & $2(4.8)$ & $7(2.5)$ \\
\hline
\end{tabular}


Table 2. Statistical analysis of variant histology versus pathologic features for in-house cases of upper urinary tract urothelial carcinoma



LVI, lymphovascular invasion; Low pT, pTa/pTis/pT1; High pT: pT2/pT3/pT4

* One variant case overlapping and 31 biopsies overlapping 
Table 3. Variant morphology, grade, and stage correlation for in-house biopsy specimens

\begin{tabular}{|l|c|c|c|c|c|c|c|c|c|}
\hline Grade (n) & \multicolumn{4}{|c|}{ High grade UC (42) } & \multicolumn{3}{c|}{ Low grade UC (27) } \\
\hline Variant morphology (n) & \multicolumn{3}{|c|}{ Present (4) } & \multicolumn{3}{|c|}{ Absent (38) } & Present (1) & \multicolumn{2}{c|}{ Absent (26) } \\
\hline Configuration (n) & P (2) & NP (1) & NA (1) & P (7) & NP (22) & NA (9) & P (1) & NP (25) & NA (1) \\
\hline Noninvasive & 0 & 1 & 0 & 3 & 15 & 4 & 1 & 25 & 1 \\
\hline Invasive & 2 & 0 & 1 & 4 & 7 & 5 & 0 & 0 & 0 \\
\hline Ta/Tis & 0 & 1 & 0 & 3 & 15 & 4 & 1 & 25 & 1 \\
\hline T1 & 2 & 0 & 1 & 3 & 5 & 4 & 0 & 0 & 0 \\
\hline T2 & 0 & 0 & 0 & 1 & 2 & 1 & 0 & 0 & 0 \\
\hline
\end{tabular}

$\mathrm{NA}=$ Not assessed due to the minute size and fragmentation of the specimen

$\mathrm{NP}=$ Non-papillary

$\mathrm{P}=$ Papillary

$\mathrm{UC}=$ Urothelial carcinoma 
Table 4. Variant morphology, grade, and pathologic stage correlation for in-house resection specimens

\begin{tabular}{|l|c|c|c|c|c|c|c|c|}
\hline Grade (n) & \multicolumn{4}{|c|}{ High grade UC (259) } & \multicolumn{4}{c|}{ Low grade UC (55) } \\
\hline Variant morphology (n) & \multicolumn{2}{|c|}{ Present (40) } & \multicolumn{2}{|c|}{ Absent (219) } & \multicolumn{2}{c|}{ Present (2) } & \multicolumn{2}{c|}{ Absent (53) } \\
\hline Configuration (n) & $\mathrm{P}(20)$ & $\mathrm{NP}(20)$ & $\mathrm{P}(138)$ & $\mathrm{NP}(81)$ & $\mathrm{P}(1)$ & NP (1) & $\mathrm{P}(53)$ & NP (0) \\
\hline Noninvasive & 2 & 2 & 27 & 3 & 1 & 1 & 46 & 0 \\
\hline Invasive & 18 & 18 & 111 & 78 & 0 & 0 & 7 & 0 \\
\hline pTa & 2 & 0 & 27 & 0 & 1 & 1 & 46 & 0 \\
pTis & 0 & 2 & 0 & 3 & 0 & 0 & 0 & 0 \\
pT1 & 5 & 2 & 44 & 7 & 0 & 0 & 5 & 0 \\
pT2 & 5 & 1 & 30 & 20 & 0 & 0 & 2 & 0 \\
pT3 & 5 & 7 & 33 & 36 & 0 & 0 & 0 & 0 \\
pT4 & 3 & 8 & 4 & 15 & 0 & 0 & 0 & 0 \\
\hline pNx & 11 & 11 & 84 & 37 & 1 & 1 & 32 & 0 \\
pN0 & 4 & 4 & 45 & 23 & 0 & 0 & 21 & 0 \\
pN1 & 1 & 1 & 7 & 9 & 0 & 0 & 0 & 0 \\
pN2 & 4 & 3 & 2 & 12 & 0 & 0 & 0 & 0 \\
pN3 & 0 & 1 & 0 & 0 & 0 & 0 & 0 & 0 \\
\hline Mx & 20 & 20 & 138 & 80 & 1 & 1 & 53 & 0 \\
M1 & 0 & 0 & 0 & 1 & 0 & 0 & 0 & 0 \\
\hline
\end{tabular}

$\mathrm{NP}=$ Non-papillary

$\mathrm{P}=$ Papillary

$\mathrm{UC}=$ Urothelial carcinoma 
Table 5. Summary of variant morphology in-house and consultation cases

\begin{tabular}{|l|l|l|}
\hline & In-House & Consultation* \\
\hline Total Cases & 383 & 181 \\
\hline Conventional UC & $337(88 \%)$ & $148(82 \%)$ \\
\hline Variant UC & $46(12 \%)$ & $33(18 \%)$ \\
\hline Squamous differentiation & $16(4.1 \%)$ & $9(4.8 \%)$ \\
\hline Inverted growth pattern & $9(2.5 \%)$ & $7(3.7 \%)$ \\
\hline Sarcomatoid** & $7(1.8 \%)$ & $9(4.8 \%)$ \\
\hline Glandular differentiation & $6(1.6 \%)$ & $6(3.2 \%)$ \\
\hline Micropapillary & $4(0.9 \%)$ & 0 \\
\hline Plasmacytoid & $2(0.6 \%)$ & $3(1.6 \%)$ \\
\hline Giant cell & $1(0.3 \%)$ & 0 \\
\hline Lymphoepithelioma-like & $1(0.3 \%)$ & 0 \\
\hline Small cell & 0 & $2(1.1 \%)$ \\
\hline Trophoblastic differentiation & 0 & $1(0.5 \%)$ \\
\hline $\begin{array}{l}\text { UTUC, upper urinary tract urothelial carcinoma; UC, urothelial } \\
\text { carcinoma. }\end{array}$ *Several consultation cases exhibited more than one variant; therefore the \\
$\begin{array}{l}\text { variant types total is greater than the variant UC total. } \\
\text { **Sarcomatoid variants identified included chondroid, rhabdoid, and } \\
\text { spindled morphologies. }\end{array}$ \\
\hline \begin{tabular}{l}
$\mid l$ \\
\hline
\end{tabular}
\end{tabular}


Table 6. Overall in-house biopsy and resection correlation with variant morphology, grade, and stage

\begin{tabular}{|c|c|c|c|c|c|c|c|c|c|}
\hline Grade (n) & \multicolumn{6}{|c|}{ High grade UC (282) } & \multicolumn{3}{|c|}{ Low grade UC (70) } \\
\hline Variant morphology (n) & \multicolumn{3}{|c|}{ Present (44) } & \multicolumn{3}{|c|}{ Absent (238) } & \multicolumn{2}{|c|}{ Present (2) } & \multirow{2}{*}{$\begin{array}{c}\text { Absent (68) } \\
\mathrm{P}(68)\end{array}$} \\
\hline Configuration (n) & $\mathrm{P}(21)$ & NP (22) & NA (1) & $\mathrm{P}(148)$ & NP (84) & NA (6) & $\mathrm{P}(1)$ & NP (1) & \\
\hline Noninvasive & 3 & 2 & 0 & 35 & 4 & 1 & 1 & 1 & 61 \\
\hline Invasive & 18 & 20 & 1 & 113 & 80 & 5 & 0 & 0 & 7 \\
\hline $\mathrm{Ta} / \mathrm{Tis}$ & 3 & 2 & 0 & 35 & 4 & 1 & 1 & 1 & 61 \\
\hline $\mathrm{T} 1$ & 5 & 4 & 1 & 45 & 9 & 4 & 0 & 0 & 5 \\
\hline $\mathrm{T} 2$ & 5 & 1 & 0 & 31 & 20 & 1 & 0 & 0 & 2 \\
\hline T3 & 5 & 7 & 0 & 33 & 36 & 0 & 0 & 0 & 0 \\
\hline $\mathrm{T} 4$ & 3 & 8 & 0 & 4 & 15 & 0 & 0 & 0 & 0 \\
\hline
\end{tabular}

$\mathrm{NA}=$ Not able to assess due to the minute size and fragmentation of the specimen

$\mathrm{NP}=$ Non-papillary

$\mathrm{P}=$ Papillary

$\mathrm{UC}=$ Urothelial carcinoma 


\section{Variant morphology in upper urinary tract urothelial carcinoma: a fourteen-year case}

series of biopsy and resection specimens

Highlights

- Upper urinary tract urothelial carcinoma exhibits a spectrum of variant morphology.

- Variant morphology frequency in biopsies and resections has not been reported.

- The frequency of variant morphology is around $12 \%$ in the general population.

- Previously reported incidences are most likely inflated due to a consultation bias. 